\title{
Eutrophication: Impacts of Excess Nutrient Inputs on Aquatic Ecosystem
}

\author{
S. S. Rathore ${ }^{1}$, P. Chandravanshi ${ }^{2}$, A. Chandravanshi $^{3}$ and K. Jaiswal ${ }^{4}$ \\ ${ }^{1,2,3}$ (Department of Aquaculture, College of Fisheries, Karnataka Veterinary, Animal and Fisheries Science \\ University, Mangalore, Karnataka, India) \\ ${ }^{4}$ (Department of Aquaculture, College of Fisheries Science, Junagadh Agricultural University, Veraval,
} Gujarat, India)

\begin{abstract}
Nutrient pollution is a growing problem for water bodies around the world. Cultural eutrophication associated with nutrient pollution can lead to unhealthy ecosystems with a lack of oxygen and biodiversity. Anthropogenic inputs of nutrients to the Earth's surface and atmosphere have increased greatly during the past two centuries. This nutrient enrichment, or eutrophication, can lead to highly undesirable changes in ecosystem structure and function, however. This study investigated ponds to determine their trophic status, measured by water chemistry and biological indicators and briefly review the process, the impacts, and the potential management of cultural eutrophication in freshwater, marine, and terrestrial ecosystems.
\end{abstract}

Keywords: Aquatic Ecosystem, Eutrophication, Nutrient Inputs, Nutrient Pollution, Trophic Status.

\section{Introduction}

Eutrophication of a water body occurs when nutrients, specifically nitrogen and phosphorus, accumulate in the water column and bottom sediments. This process naturally occurs in lakes and ponds at a very slow pace as organic matter builds up during ecological succession. However, if eutrophication is accelerated through human activity it can become detrimental to ecosystems [1]. High nutrient levels promote blooms of photosynthetic life, which will eventually die and become food for aerobic bacteria. The proliferation of bacteria that follows can lead to decreased dissolved oxygen levels and a consequential drop in biodiversity [2]. Cultural eutrophication is the term for nutrient pollution in an aquatic system caused by anthropogenic sources. Only recently have people begun to recognize the threat that this pollution is presenting to pond ecosystems [1]. Some major sources of nutrient loading into ponds include runoff from fertilizers, construction deposition, and leakage from septic systems [2] [3]. These are examples of non-point sources and are much more difficult to identify and remedy than point sources, but are the major causes of eutrophication. Control depends heavily on stopping the external flow of nutrients into water systems, but even so internal cycling in the water system can make recovery difficult to attain [2].

\section{Eutrophication and Water Chemistry}

Water chemistry is of great importance to freshwater systems such as ponds. It has an effect on species composition and can influence which species might have competitive advantages over others to become dominant [4]. Phytoplankton have an important presence in ponds as primary producers. The three major groups of phytoplankton are green algae, cyanobacteria, also known as blue-green algae, and diatoms. There are certain chemical compositions that would be optimal for each of these groups, and their relative abundances can reflect those preferences. All phytoplankton need nitrogen and phosphorus to survive, and their growth has been shown to correlate with the chemical concentrations of these nutrients [5]. Nutrient levels have such a direct impact on phytoplankton populations because they generally exist in low concentrations in natural waters [6]. Therefore, the growth of phytoplankton populations is limited by their access to phosphorus and nitrogen for metabolic processes. On the other hand, if these nutrients are present in excess, populations can flourish. For example, ecosystem health guidelines for an oligotrophic lake dictates that it should have less than $0.01 \mathrm{mg} / \mathrm{L}$ of phosphorus and less than $2 \mathrm{mg} / \mathrm{L}$ of nitrogen, correlating with phytoplankton production levels of 7 to 25 $(\mathrm{gC}) /\left(\mathrm{m}^{2}\right)$. By contrast, a eutrophic lake would have over $0.03 \mathrm{mg} / \mathrm{L}$ of phosphorus and over $5 \mathrm{mg} / \mathrm{L}$ of nitrogen, correlating with 350-750 $(\mathrm{gC}) /\left(\mathrm{m}^{2}\right)$ [4] [7]. In this example, doubling the nutrient concentrations increased the carbon fixation rate of algae up to 30 times. However, these standards have been specifically established for lakes, which are, by definition, larger than ponds [1]. Sondergaard et al. suggest that nutrients might be of lesser importance to smaller bodies because of loweryield of chlorophyll per unit of nitrogen or phosphorus [8]. This could mean that even with higher phosphorus levels, phytoplankton production levels would remain lower. Regardless of the water system, algal requirements for nitrogen, phosphorus, and carbon have been expressed in a ratio called the Redfield ratio as follows, 40C : 7N : 1P [4]. This ratio expresses just how little nitrogen, and 
especially phosphorus, algae require for primary production. It is easy to see that in an environment where nitrogen or phosphorus are present in excess, phytoplankton populations have the great potential to multiply.

Phosphorus, specifically, has been identified as the most important nutrient in controlling eutrophication of freshwater systems [9]. It exists in various forms, but orthophosphate is the only type available for autotroph assimilation. Total phosphorus includes all forms of phosphorous, both organic and inorganic, found in the water column [3]. It is important to consider the total phosphorus inventory of a lake or pond when determining its eutrophication level, because under certain conditions particulate and dissolved phosphorus can be converted to orthophosphate. These internal mechanisms that release $\mathrm{P}$ bound to sediments are influenced by environmental factors, such as low dissolved oxygen levels [9]. Bacteria in organic matter are largely responsible for creating conditions for the redox reactions that cause phosphorus in the sediments to be released back into the water through their metabolic activity. Under low dissolved oxygen, these redox reactions occur more readily [10]. This can create a positive feedback system, as low dissolved oxygen is a symptom of eutrophic waters, which would then become even more nutrient polluted due to the release of $\mathrm{P}$ from sediments as a result of hypoxia. On the other hand, there are also certain conditions that act to keep phosphorus bound to sediments. Lakes with high iron concentrations have little release of $\mathrm{P}$ from sediments, while lakes with lower iron experience regular seasonal cycling [11]. For this reason, it is important to consider the impacts of internal cycling when studying eutrophication of aquatic bodies.

\subsection{Effects of Eutrofication on Lakes and Reservoirs}

A vital key to the management of lake and reservoir eutrophication has been the development of models linking water body nutrient concentrations to aspects of water quality that are considered by the public to be important and worth preserving [12]. Perhaps the most commonly identified quality variable of Concern in aquatic ecosystems [13] is the accumulation of nuisance levels of algal biomass, which are easily observed by the public. Moreover, the reduction of algal biomass to levels that are acceptable to the public has been a feature common to all successful eutrophication control efforts [12]. As would be expected from Liebig's law of the Minimum, there is a remarkable consistency in the response of algal biomass to nutrient enrichment. Strong positive relationships between algal biomass and nutrient loading have been observed in most lakes and reservoirs that have been studied [14] [15]. Excessive nutrient enrichment also has many additional effects on the biology, chemistry, and human use of lakes and reservoirs, however. These secondary effects are frequently deleterious, and may be of great concern to users of the resource (Table 1). For example, eutrophic lakes are typically characterized by shifts towards dominance of the phytoplankton by blue-green algae (cyanobacteria), some of which produce compounds that are more toxic than cobra venom [16] [17].

Table 1. Effects of eutrophication on lakes and reservoirs (modified from [12].

\begin{tabular}{|l|}
\hline Increased biomass of freshwater phytoplankton and periphyton \\
\hline Shifts in phytoplankton species composition to taxa that may be toxic or inedible (e.g. bloom-forming cyanobacteria) \\
\hline Changes in vascular plant production, biomass, and species composition \\
\hline Reduced water clarity \\
\hline Decreases in the perceived aesthetic value of the water body \\
\hline Taste, odor, and water supply filtration problems \\
\hline Possible health risks in water supplies \\
\hline Elevated pH and dissolved oxygen depletion in the water column \\
\hline Increased fish production and harvest \\
\hline Shifts in fish species composition towards less desirable species \\
\hline Increased probability of fish kills \\
\hline
\end{tabular}

In order to predict the effects of $\mathrm{N}$ and $\mathrm{P}$ inputs on receiving waters, it is necessary to be able to predict how water body nutrient concentrations vary as the external $\mathrm{N}$ and $\mathrm{P}$ inputs are changed. The development of quantitative models that relate external nutrient inputs to the resulting water column concentrations of nutrients in the water body itself was a second key development in eutrophication research. This conceptual advance resulted from the introduction of mass balance approaches to aquatic ecosystems; the mass balance approach apparently was not broadly applied to eutrophication modeling until [18]. In the 30 years since the publication of Vollenweider's report, however, a rigorous quantitative framework has developed to predict the responses of freshwater lakes and reservoirs to eutrophication. Essential to this framework are the calculations of mass budgets for both $\mathrm{N}$ and $\mathrm{P}$, and the parallel calculation of a hydraulic budget for the water body.

\subsection{Effects of Nutrient Inputs on Rivers and Streams}

Although the majority of freshwater eutrophication research during the past several decades has focussed on lakes and reservoirs, the nutrient enrichment of flowing waters is also of great concern. In the continental US, for example the mean total phosphorus (TP) concentration of streamwater at 381 riverine sites was found to be $130 \mathrm{mg} \mathrm{m}^{-3}$ [19]. This value greatly exceeds the mesotrophic-eutrophic TP boundary of $75 \mathrm{mg}$ 
$\mathrm{m}^{-3}$ recently proposed [20]. In a more recent study, [21] found that $61 \%$ of 2048 cataloging units failed to meet the EPA standard. These data suggest that the water quality in a majority of US streams and rivers is poor from the standpoint of eutrophication [22].

Although many streams and rivers worldwide currently exhibit high nutrient concentrations, a prevailing view for many years held that many rivers are insensitive to nutrient inputs [23]. This argument was based upon the assumption that other physical, chemical, and biotic factors potentially restrict the effects of nutrient enrichment on algal growth in rivers and streams (Table 2). For example, light availability can influence the biomass accumulation of benthic algae (periphyton) in low-order streams shaded by extensive forest canopies [24]. Restriction of light penetration into the water column by high concentrations of inorganic suspended solids also can potentially limit the growth of both benthic and suspended algae in rivers, just as it can restrict phytoplankton biomass in turbid reservoirs [25]. Furthermore, the hydraulic flow regime can greatly alter periphyton standing crops in flowing waters, and herbivore grazing often is noted as an additional biological constraint on periphyton growth and productivity. For many years, flowing waters thus were frequently perceived as nutrient saturated, because factors such as light limitation and short hydraulic residence times should restrict or prevent any potential algal responses to nutrient enrichment.

Table 2. Effects of eutrophication on stream ecosystems (modified from [26] as cited in [27])

\begin{tabular}{|l|}
\hline Increased biomass and changes in species composition of suspended algae and periphyton \\
\hline Reduced water clarity \\
\hline Taste and odor problems \\
\hline Blockage of intake screens and filters \\
\hline Fouling of submerged lines and nets \\
\hline Disruption of flocculation and chlorination processes at water treatment plants \\
\hline Restriction of swimming and other water-based recreation \\
\hline Harmful diel fluctuations in pH and in dissolved oxygen concentrations \\
\hline Dense algal mats reduce habitat quality for macroinvertebrates and fish spawning \\
\hline Increased probability of fish kills \\
\hline
\end{tabular}

\subsection{Effects on Estuarine and Coastal Marine Ecosystems}

Streams and rivers serve as rapid conduits for anthropogenic pollutants to estuarine and coastal marine environments. For example, fertilizer inputs dominate net anthropogenic inputs of $\mathrm{N}$ in most drainage basins supplying water to the North Atlantic Ocean. In addition, the anthopogenic deposition rates of oxidized (NOy) and reduced $(\mathrm{NHx})$ forms of $\mathrm{N}$ to these same 13 watersheds are estimated to exceed pre-industrial inputs by several-fold [28]. Increased inputs of P eroded from the landscape and carried from human wastewater into the world's rivers have increased global fluxes of $\mathrm{P}$ to the oceans almost three fold from historic levels of ca. 8 million metric tonnes per year to current loadings of ca. 22 million metric tonnes per year [29]. These trends in anthropogenic $\mathrm{N}$ inputs are of great concern because nutrient limitation of algal production has been demonstrated or inferred in many estuarine and marine waters [30] [31] [32]. Not surprisingly, wide-ranging effects of this nutrient enrichment are easily visible in coastal ecosystems (Table 3), and the degradation in water quality that accompanies marine eutrophication can have significant socioeconomic impacts [33] [34] [35].

Table 3. Effects of eutrophication on estuarine and coastal marine ecosystems (modified from [12])

\begin{tabular}{|l|}
\hline Increased biomass of marine phytoplankton and epiphytic algae \\
\hline Shifts in phytoplankton species composition to taxa that may be toxic or inedible (e.g., bloom forming dinoflagellates) \\
\hline Increases in nuisance blooms of gelatinous zooplankton \\
\hline Changes in macroalgal production, biomass, and species composition \\
\hline Changes in vascular plant production, biomass, and species composition \\
\hline Reduced water clarity \\
\hline Death and losses of coral reef communities \\
\hline Decreases in the perceived aesthetic value of the water body \\
\hline Elevated pH and dissolved oxygen depletion in the water column \\
\hline Shifts in composition towards less desirable animal species \\
\hline Increased probability of kills of recreationally and commercially important animal species \\
\hline
\end{tabular}

\section{Biological Indicators of Eutrophication}

Algae are often used as biological indicators to measure freshwater nutrient levels. Phytoplankton populations have a positive, linear correlation with phosphorus increase, and the Redfield ratio can be particularly useful to determine whether nutrients are available in adequate levels for growth [36]. However, this relationship between phytoplankton biomass and nutrient concentration has been found to be less strong in ponds, because of submerged vegetation and activity of large zooplankton [37]. Knowing the species makeup of the algal community is more telling, because the presence and abundance of certain groups can indicate different 
environmental conditions. Cyanobacteria, green algae, and diatoms all flourish under different chemical parameters. Cyanobacteria"es capacity for nitrogen fixation allows them to dominate freshwater systems when $\mathrm{N}: \mathrm{P}$ ratios are low [38]. Heterocyst formation is negatively correlated with dissolved inorganic $\mathrm{N}$ in the water, so they are easily able to out compete diatoms and green algae that cannot fix their own nitrogen [6], [39]. However, cyanobacteria have no competitive edge in phosphorous competition, so when N:P ratios are high there is generally more equal balance of all phytoplankton groups [39].

Species composition is also useful in studying the health of a pond, because different species flourish under different conditions. Palmer has identified certain species of algae to be indicative of clean water supplies, including Staurastrum and Pinnularia. He associates other species, such as Euglena (Euglenophyceae), Oscillatoria (cyanobacteria), Anabeana (cyanobacteria), and Microcystis (cyanobacteria), with polluted waters [40]. There have been many other species and genera of algae, since Palmer, that have been identified as common to ponds, lakes, eutrophic bodies, oligotrophic bodies, acidic waters, etc. [41]. If these species are present in a body of water, they can provide an indication of environmental conditions. Freshwater plankton communities also vary with seasonal succession [42] [43]. Succession is largely driven by temperature, light penetration, and nutritional concentration [42]. Algae vary in their optimum range for these conditions, and so with changing conditions, different species can proliferate.

Nevertheless, algae are not the only biological component of pond ecosystems and, therefore, should not be the sole indicators of ecosystem health. Especially because studies have shown ponds, specifically, to have a lesser association between nutrient levels and algae biomass, a whole-ecosystem, community structure evaluation is critical to assessing the state of a pond [37] [36] [44]. To create a standard method for surveying pond health, [1] identified five groups as principal: plants, Gastropoda (snails and slugs), Coleoptera (beetles), Odonata (dragonflies and damselflies), and Amphibia (amphibians). These groups are representative because they occupy different trophic levels within the pond, demonstrate a variety of dispersal techniques, and have some degree of information known about their environmental tolerance [1] [45]. Ephemeroptera (mayfly) larvae have been used in eutrophication studies as well, because they are known to be sensitive to low dissolved oxygen levels [46]. Aside from using biological indicators such as these to determine the health of the ecosystem, it is also important to understand the various aspects of pond biology because any action taken to address eutrophication will inevitably impact other aspects of the food web. This study focuses on the health of three small ponds in Massachusetts. Gilmore Pond is of critical importance to my study, because of concerns held by the pond's owners, and Wildcat and Peacock Pond are used as comparisons. The ponds were studied from late summer through the fall for different chemical and biological criteria. Upon comparing these data, the trophic state and ecological health of Gilmore Pond will be assessed and management options considered. I hypothesize that Gilmore and Peacock Pond will both be eutrophic systems, based on personal and community perception of these ponds, but that Wildcat Pond will not be eutrophic because it is a drinking water source and feeds into a lake that meets Clean Water Act criteria.

\section{Management Strategies}

Deciding how to manage a freshwater pond is the next step after assessing its trophic state. There are many different management options available that have been tested both in the scientific community and autonomously by pond and lake managers. These methods can be broadly grouped into physical, chemical, or biological control techniques. No one method is ranked highest among the others, as each case of eutrophication has to be managed uniquely based on the specific circumstances. However, understanding those circumstances can help managers to choose the best technique for their pond. Careful treatment and understanding the repercussions of management action is critical to long-term success [47]. There is one course of action that has been widely acknowledged as the first step in reversing cultural eutrophication, and that is controlling the external loading of phosphorous into the water system [48] [49] [2] [4]. Without first reducing nutrient inputs, further management is not likely to yield high success, especially in the long-term. However, stopping inputs alone is often not enough for successful eutrophication reversal because it does not address internal cycling. Another element to remember in reviewing the following management plans is that they were largely created for the purpose of lake management. Gilmore Pond must be treated as a pond in its assessment as well as its management. Nonetheless, limiting phosphorus inputs is of utmost importance.

\subsection{Physical}

\subsubsection{Dredging}

Dredging is a technique for eutrophication control when the nutrient concentrations are largely the result of internal recycling [48]. There are several ways to dredge, for example wet vs. dry, but ultimately it involves removal of the bottom sediments that are rich with phosphorus and perpetuating the growth of algae [47] [50]. Dredging can also have the effect of deepening a pond. This could change the dynamics of the ecosystem by altering the abiotic regimes of the water column and also act to dilute nutrient concentrations with 
the addition of pond volume [47]. Another effect of dredging is the possible exposure of an otherwise stifled seed bank. If a pond has not had macrovegetation growth in several years, there is still the possibility of seeds from historic plant communities residing dormant in the bottom sediments. Dredging can expose these seeds to more ideal conditions and allow macrovegetation to reestablish, creating a photosynthetic competitor for dominant algal communities [49]. After removing sediment, it has to be disposed of in a designated area. This area must be large enough to contain all of the nutrient-rich waters that will inevitably be removed with the spoils. Runoff from improper containment of removed sediment is a common problem associated with dredging that can be avoided with proper planning. To be sure that the removed sediments are will not be hazardous, analysis for potentially toxic compounds such as heavy metals and chlorinated hyrdocarbons, must be carried out before dredging can begin [50]. Certain precautions and permitting is required if these materials are found in high concentrations, and can heavily contribute to the total cost. Though dredging is an efficient way of removing $\mathrm{P}$ trapped in sediments, it does have certain drawbacks. It is a large operation that is expensive and invasive. It should only be considered if the habitat is in serious decline and reconstruction is the only option [47].

\subsubsection{Aeration}

Aeration is a technique that acts to increase oxygen levels of a pond and minimize stratification. Oxygen is connected to eutrophication control because anoxic environments can release $\mathrm{P}$ from the soil to stimulate internal cycling. Therefore, with more oxygen and a more homogenous distribution, internal cycling is limited [47]. Oxygenation by aeration can also benefit zooplankton populations by lowering the $\mathrm{pH}$ and creating more tolerable oxygen and temperature conditions at the depths, allowing them to spread their range. Having a wider range of suitable habitat can reduce predation on zooplankton, so that they might increase their own predation on undesirable algae populations [51]. Because aeration management largely deals with oxygenation, it should be considered when phosphorus release is connected with low DO levels. The initial cost of installing an aeration pump is can be high, usually between $\$ 50$ to $\$ 800 /$ acre, in addition to annual costs for use and maintenance [47].

\subsection{Chemical}

\subsubsection{Algicide}

Much like using herbicides to kill unwanted terrestrial vegetation, algicides can be used to kill unwanted algae in freshwater bodies. Copper sulfate is the most commonly used algicide [47] [50]. Copper interferes with photosynthetic processes in algae, and thereby retards their growth [47]. Copper algicides have been particularly effective against cyanobacteria, but, as a result oftheir widespread use, certain strains of Anabaena, a genus of cyanobacteria classically associated with eutrophication, and a few species of green algae have developed resistance. Algicides should only be used as a last resort because of their unintentional negative impacts [47]. Copper is toxic to fish as well as other microscopic organisms, such as dinoflagelletes and diatoms, and effects of chronic exposure on other organisms higher in the trophic pyramid have not yet been fully realized [50] [47]. Algaecides also create toxic side effects when they disrupt the cells of noxious cyanobacteria and their toxins are released into the environment [47] [48]. Algicide treatment does not address the root causes of eutrophication, and can actually perpetuate eutrophic conditions by depleting dissolved oxygen. It is not effective in the long term, and additional applications are sometimes required [50].

\subsubsection{Phosphorus Binding}

Once external phosphorus inputs are controlled, there are chemicals that can be applied to bind phosphorus already in the system to suppress internal inputs. Flocculents made from aluminum, iron, or calcium are the most commonly used compounds to remove particulates from the water column [47] [48]. Aluminum sulfate, or alum, has been the most widely used and successful of these salts. When aluminum sulfate enters the water, aluminum hydroxide $\left(\mathrm{Al}(\mathrm{OH})_{3}\right)$ forms and the $\mathrm{pH}$ of the water decreases. This aluminum-based floc has the capacity for high $\mathrm{P}$ adsorption, and phosphates are stripped from the water column as the compound settles to the sediments [52]. To most effectively reduce internal cycling of phosphorus, it must then be fixed, or bound, so that it cannot escape from the sediment where it accumulates. Luring and Oosterhout found this combination, that they call "Flock and Lock" (flocculent and fixative), to be the most effective way to reduce both chlorophyll-a and phosphorus concentrations of small, shallow lakes [48]. The fixative that they suggest is lanthuim-modified bentonite Phoslock, a product developed by Australia's Commonwealth Scientific and Industrial Research Organization (CSIRO) [53]. Fixation occurs when phosphorus, in the form of orthophosphate, is permanently bound to lanthanum [54]. The "flock and lock" method is most effective when external phosphorus loads are no longer overwhelming the ecosystem and when internal cycling becomes the main source of phosphorus to algal populations. Results from a "flock and lock" approach can be observed rapidly, but are not necessarily lasting [48]. Treatment is generally effective for about five years [50]. Success is 
also dependent on the $\mathrm{pH}$, alkalinity, and DO levels of the water [13]. Phosphorus inactivation with aluminum sulfate, a popular "flocking" compound, works best in hard waters with circumneutral $\mathrm{pH}$ [50]. In soft water, it is easier for $\mathrm{pH}$ to fall below 6 , under which conditions aluminum can change into forms associated with toxic effects [50] [52].

\subsubsection{Dyes}

Dyes are a chemical treatment without toxic side effects. Dyes act to control phytoplankton by obstructing light access. This technique has been successful, but is generally used on small, ornamental ponds and not often in Massachusetts [47].

\subsubsection{Barley Straw}

Using barley straw to control eutrophication is a new technique that continues to be researched. Barley straw management works by packing barley, about 250-lbs per acre, into loose mesh bags at the beginning of the summer, when conditions are starting to become favorable for algae blooms [55]. When barley straw sits in water, decomposition by fungi cause a chemical reaction that inhibits the growth of algae [56]. Researchers have reported successful inhibition of nuisance cyanobacteria such as certain species of Microcystis and Anabaena, as well as green algae like Scenedesmus and Spirogyra [57]. Decomposition requires a high oxygen environment, so it is best to have the bags floating on the surface near shore. It can take a few weeks for the compounds that inhibit algal growth to build up, but effects are likely to last the remainder of the summer at which point the bags can be removed [55]. Though the process is not well understood, some research suggests that it might also have the effect of lowering P concentrations [56]. The effects of barley straw are variable, with greater success in bodies with long residence time [56] [55]. It can require multiple applications, but research from England suggests that it can be effective in the long term [55] [56]. The EPA has not yet assessed barley straw, so it cannot be used on public land, but is a potential management option for privately owned ponds [56].

\subsection{Biological}

Biomanipulation alters ecosystem characteristics to stimulate a change that will correct the problems associated with eutrophic systems. It involves complex interactions that are not completely understood and can have mixed results as a consequence.

\subsubsection{Top-Down Control}

Food web interactions are a major component of ecosystem dynamics, and are closely associated with the abiotic environment. Problems with eutrophication are often centered around nuisance algal blooms. Topdown biomanipution acts to control algal populations through increased grazing by zooplankton. Large populations of zooplankton in lakes have been associated with clearer water and low algal populations [47]. This has been seen even in lakes that maintain high phosphorus levels [51].

There are several different ways to go about stimulating zooplankton populations. The simplest way is to directly add zooplankton to the effected pond [51]. Other planktivores, that are not zooplankton, could be added, but stocking in this way is less successful because they are likely to increase predation on both phytoplankton and zooplankton, which is counter-productive [47]. In research about trophic level interactions and their effects on algal populations, it was shown that systems with an odd number of trophic levels, one or three, had higher algal biomass than systems with even numbers, two or four [11]. To support a four level system, piscovorous fish can be added that will graze on zooplankton predators. Unfortunately, this is more of a suggestion for larger lakes, because ponds are likely already at carrying capacity for higher trophic level species, so the effects would be short lived. A two level system might be more effective for a small pond and might be achieved by removing predators of planktivorous zooplankton [47]. The results of biomanipulation are not reliably predictable and will certainly vary between cases. However, it is generally more successful in smaller bodies, where the environment is more easily manipulated [55].

\subsubsection{Restoration of Submerged Vegetation}

In certain cases of eutrophication, algae populations become dominant and out compete submerged vegetation for light and photosynthesis resources. Submerged vegetation is very characteristic of ponds and, without it, reaching a clear-water state might not be possible. Reestablishing aquatic plant populations that once grew in a eutrophic pond can help keep algae blooms down by creating competition for light and nutrients. After an initial treatment, such as dredging or alum application, populations may come back naturally, but intentional introduction can also be applied. Species chosen should be native and should be tested in a small area before being introduced to the entire pond. Charophytes are generally good for maintaining a healthy ecosystem [49]. 


\subsection{No action}

Another management option is to take no action. To control inputs of nutrients would still be advised under this solution, but management would end there. Ponds are natural systems that go through changes during their lifespan which is finite. A pond that appears to be degraded in the public eye, in nature might support a complex and flourishing ecosystem [47].

\section{Conclusion}

This study contributes to the pool of knowledge that is developing about pond ecology and eutrophication. Based on water chemistry analysis, this study presents the possibility that the nutrient threshold level indicating eutrophication in lakes should be altered for the study of ponds, because of their unique properties. It may be important to pursue this possibility with haste, because eutrophication is among the many current environmental issues associated with global climate change [58] [59]. Biota of shallow lakes and ponds are predicted to be impacted by rising temperatures. Rising temperatures would favor cyanobacteria populations, because their optima growth temperature is higher than that of other phytoplankton, augmenting the problem of harmful cyanobacterial blooms in eutrophic systems [59] [60]. Extreme weather events associated with climate change are also likely to impact the stability of alternative states in eutrophic ponds, because extreme events can prompt shifts between turbid and clear water states [58]. With the uncertain environmental future posed by climate change, there is a need for continued research on ponds and the unique way they experience cultural eutrophication.

\section{References}

[1] B. Oertli, D. Joye., E. Castella, R. Juge, A. Lehmann and J. Lachavanne, PLOCH: a standardized method for sampling and assessing the biodiversity in ponds, Aquatic Conservation: Marine and Freshwater Ecosystems, 15, 2005, 665-679.

[2] S.R. Carpenter, N. Caraco, D. Correll, R. Howarth, A. Sharpley and V. Smith, Nonpoint pollution of surface waters with phosphorus and nitrogen, Ecological Applications, 8(3), 1998, 559-568.

[3] D.J. Velinsky, Ecologically Based Small Pond Management, The Limnology of Small Ponds, 2, 2004 , 3-67.

[4] D.W. Schindler and E.J. Fee, Experimental lakes area: whole-lake experiments in eutrophication, Journal of Fisheries Research Board of Canada. 31(5), 1974, 937-953.

[5] D.M. Soballe, and B.L. Kimmel, A large-scale comparison of factors influencing phytoplankton abundance in rivers, lakes, and impoundments, Science, 68(6), 1987, 1943-1954.

[6] P. Sze, A Biology of the Algae, 3rd ed. Boston, McGraw-Hill, 1998.

[7] H. Olem, and G. Flocks, Lake and reservoir restoration guidance manual, 2nd ed. Washington, D.C., U.S. Environmental Protection Agency, Office of Water, 1990.

[8] M. Sondergaard, E. Jeppesen, P.J. Jens, Pond or lake: does it make any difference, Archiv fur Hydrobiologie, 162(2), 2005, 143165.

[9] D.L. Correll, The role of phosphorus in the eutrophication of receiving waters: a review, Journal of Environmental Quality, 27, 1998, 261-266

[10] R.G. Wetzel, Limnology: lake and river ecosystems, 3rd ed. San Diego, Academic Press, 2001.

[11] V.H. Smith and D.W. Schindler, Eutrophication science: where do we go from here, Trends in Ecology and Evolution. 24(4), 2009, 201-207.

[12] V.H. Smith, Cultural eutrophication of inland, estuarine, and coastal waters, In: Pace, M.L, Groffman, P.M. (Eds.), Successes, Limitations and Frontiers in Ecosystem Science. Springer, New York, 1998, 7-49.

[13] K.H. Reckhow, S.C. Chapra, Engineering Approaches for Lake Management, Vol. 1: Data Analysis and Empirical Modeling, Butterworth, Boston, MA,1983.

[14] P.J. Dillon, F.H. Rigler, 1974. The phosphorus-chlorophyll rela- tionship in lakes. Limnology and Oceanography, 19, 767-773.

[15] J.R. Jones and R.W. Bachmann, 1976. Prediction of phosphorus and chlorophyll levels in lakes. Journal of the Water Pollution Control Federation, 48, 2176-2182.

[16] O.M. Skulberg, G.A. Codd and W.W. Carmichael, Toxic blue-green algal blooms in Europe: a growing problem, Ambio, 13, 1984, 244-247.

[17] W.W. Carmichael, Toxic freshwater blue-green algae (cyanobacteria): an overlooked health threat, Health Environ. Digest, 5, 1991, $1-4$.

[18] R.A. Vollenweider, Scientific Fundamentals of Lake and Stream Eutrophication, With Particular Reference to Phosphorus and Nitrogen as Eutrophication Factors. (Technical Report DAS/ DSI/68.27). OECD, Paris, France, 1968.

[19] R.A. Smith, R.B. Alexander and M.G. Wolman, Water quality trends in the nation's rivers, Science, 235, 1987, 1507-1615.

[20] W.K. Dodds, J.R. Jones and E.B. Welch, Suggested classification of stream trophic state: distributions of temperate stream types by chlorophyll, total nitrogen, and phosphorus. Water Research, 32, 1998, 1455-1462.

[21] R.A. Smith, G.E. Schwarz and R.B. Alexander, Regional interpretation of water-quality monitoring data, Water Resources Research, 33, 1997, 2781-2798.

[22] F.S. III Chapin, B.H. Walker, R.J. Hobbs, D.U. Hooper, J.H. Lawton, O.E. Sala and D. Tilman, Biotic control over the functioning of ecosystems, Science, 277, 1997, 500-504.

[23] H.B.N. Hynes, 1969, The enrichment of streams. Eutrophication: Causes, Consequences, Correctives. National Academy of Sciences, Washington, D.C, 188-196.

[24] S.V. Gregory, Effects of Light, Nutrients and Grazing on Periphyton Communities in Streams. Ph.D. thesis, Oregon State University, Corvallis, OR, 1980.

[25] M.V. Hoyer and J.R. Jones, 1983. Factors affecting the relation between phosphorus and chlorophyll a in midwestern reservoirs, Canadian Journal of Fisheries and Aquatic Sciences, 40, 192-199.

[26] J.M. Quinn, Guidelines for the Control of Undesireable Biological Growths in Water (Consultancy Report No.6213/2). Water Quality Centre, Hamilton, New Zealand, 1991. 
[27] US EPA, National Nutrient Assessment Workshop, Proceedings, December 4-6, 1995. (US EPA 822-R-96-004) Office of Water, US Government Printing Office, Washington, D.C., 1996.

[28] R.W. Howarth, G. Billen, D. Swaney, A. Townsend, N. Jaworski, K. Lajtha, J.A. Downing, R. Elmgren, N. Caraco, T. Jordan, F. Berendse, J. Freney, V. Kudeyarov, P. Murdoch and Z. Zhao-Liang, Regional nitrogen budgets and riverine N \& P fluxes for the drainages to the North Atlantic Ocean: natural and human infuences. Biogeochemistry, 35, 1996, 75-139.

[29] R.W. Howarth, H. Jensen, R. Marino, H. Postma, Transport to and processing of P in near-shore and oceanic waters. In: Tiessen, H. (Ed.), Phosphorus in the Global Environment: Transfers, Cycles and Management. SCOPE54. Wiley, Chichester, UK, 1995, 323345 .

[30] R.E. Hecky, P. Kilham, Nutrient limitation of phytoplankton in freshwater and marine environments: a review of recent evidence on the effects of enrichment, Limnology and Oceanography, 33, 1988, 796-822.

[31] R.W. Howarth, Nutrient limitation of net primary production in marine ecosystems, Annual Review of Ecology and Systematics, 19,1988, 898-910

[32] J.A. Downing, Marine nitrogen:phosphorus stoichiometry and the global N:P cycle. Biogeochemistry, 37, 1997, $237-252$.

[33] S.E. Shumway, A review of the e€ects of algal blooms on shellfish and aquaculture. Journal of the World Aquacultural Society, 21, 1990, 65-104.

[34] Bundy, M.M., Estuarine management from a global economic perspective, Water Science and Technology 26, 1992, $2735-2739$.

[35] E. Culotta, Red menace in the world's oceans, Science, 257, 1992, 1476-1477.

[36] D.W. Schindler, R. Hecky, D. Findlay, M. Stainton, B. Parker, K. Paterson, K. Beaty, M. Lyng and S. Kasian, Eutrophication of lakes cannot be controlled by reducing nitrogen input: results of a 37-year whole-ecosystem experiment, PNAS, 105(32), 2008, 11254-11258.

[37] S. Teisser, A. Peretyatko, S. Backer and L. Triest, Strength of phytoplankton-nutrient relationship: evidence from 13 biomanipulated ponds, Hydrobiologia, 689, 2012, 147-159.

[38] D.W. Schindler, Evolution of phosphorus limitation in lakes, Science. 1977, 260-262.

[39] V.H. Smith, Low nitrogen to phosphorus ratios favor dominance by blue-green algae in lake phytoplankton, Science. 221(4611), 1983, 669-671

[40] C.M. Palmer, Algae in water supplies: an illustrated manual on the identification, significance, and control of algae in water supplies, Washington, D.C.: U.S. Department of Health, Education, and Welfare, Public Health Service, 1959.

[41] J.D. Wehr and R.G. Sheath. Freshwater algae of North America: ecology and classification. Amsterdam: Academic Press, 2003.

[42] G. E. Hutchinson, A treatise on limnology: introduction to lake biology and the limnoplankton. New York: J. Wiley \& Sons, Inc., 1967.

[43] R.G. Wetzel, Limnology: lake and river ecosystems. 3rd ed. San Diego: Academic Press, 2001

[44] L.E. Shubert, Algae as Ecological Indicators. London: Academic Press, 1984.

[45] N.S.L. Menetrey, B. Oertli, and J. Lachavanne, Looking for metrics to assess the trophic state of ponds. Macroinvertebrates and amphibians, Aquatic Conservation: Marine and Freshwater Ecosystems, 15, 2005, 653-664

[46] N. Menetrey, B. Oertli, M. Sartori, A. Wagner and J. Lachavanne, Eutrophication: are mayflies good bioindicators for ponds, Hydrobiologia, 597, 2008, 125-135.

[47] K. Wagner, Commonwealth of Massachusetts. Executive Office of Environmental Affairs. Practical Guide to Lake Management in Massachusetts. Westford, MA, 2004.

[48] M. Lurling and F.V. Oosterhout, Controlling eutrophication by combined bloom precipitation and sediment phosphorus inactivation, Water Research, 47, 2013, 6527-6537.

[49] S. Hilt, E. Gross, M. Hupfer, H. Morscheid, J. Mahlmann, A. Melzer, J. Poltz, S. Sandrock, E.M. Scharf, S. Schneider, W.K. van de, 2006, Restoration of submerged vegetation in shallow eutrophic lakes -a guideline and state of the art in Germany, Limnologica, 36, 2006, 155-171.

[50] H. Olem and G. Flocks, Lake and reservoir restoration guidance manual. 2nd ed. Washington, D.C.: U.S. Environmental Protection Agency, Office of Water, 1990.

[51] J. Shapiro, V. Lamarra, M. Lynch, Biomanipulation: an ecosystem approach to lake restoration, Proceedings of a Symposium on Water Quality Management, 1975, 85-96.

[52] G.D. Cooke, E.B. Welch, A. Martin, D. Fulmer, J. Hyde and G. Schrieve, Effectiveness of Al, Ca, and Fe salts for control of internal phosphorus loading in shallow and deep lakes, Hydrobiologia, 253, 1993, 323-335.

[53] G. B. Douglas, 2002. US Patent 6350383: Remediation material and remediation process for sediments.

[54] P. SePRO, How Phoslock Works, 27 Apr. 2014. http://www.sepro.com/phoslock/How-Phoslock-Works.aspx.

[55] S. McComas, Lake and pond management guidebook. Boca Raton, Fla.: Lewis Publishers, 2003.

[56] C. Lembi, University of Purdue. Botany and Plant Pathology. Barley Straw for Algae Control. 2002.

[57] H.R. Islami, and Y. Filizadeg, Use of Barley Straw to Control Nuisance Freshwater Algae, American Water Works Association. 103, 2011, 111-118.

[58] M. Scheffer, and E.H. van Nes, Shallow lakes theory revisited various alternative regimes driven by climate, nutrients, depth and lake size, Hydrobiologia, 584, 2007, 455-466.

[59] H.W. Paerl, and V.J. Paul, Climate change: links to global expansion of harmful cyanobacteria, Water Research, 46, 2012, 13491363.

[60] R.D. Roberts and T. Zohary, Temperature effects on photosynthetic capacity, respiration, and growth rates of bloom-forming cyanobacteria, New Zealand Journal of Marine and Freshwater Research, 21, 1987, 391-399. 